\title{
Effect of dominant follicle persistence on follicular fluid oestradiol and inhibin and on oocyte maturation in heifers
}

\author{
M. Mihm¹, N. Curran'1, P. Hyttel2, P. G. Knight ${ }^{3}$, M. P. Boland ${ }^{4}$ and J. F. Roche ${ }^{1}$ \\ ${ }^{1}$ Faculty of Veterinary Medicine, University College Dublin, Dublin, Ireland; 'Department of Anatomy and Physiology, \\ Royal Veterinary and Agricultural University, 1870 Frederiksberg C, Denmark; 'School of Animal and Microbial Sciences, \\ University of Reading, Reading, UK; and ${ }^{4}$ Faculty of Agriculture, University College Dublin, Dublin, Ireland
}

The aim of the present study was to characterize in detail the cytoplasmic and nuclear morphology of cattle oocytes recovered from follicles that are dominant for more than 9 days (with low fertility after ovulation), and to relate morphological changes to intrafollicular markers of follicle health. Beef heifers received prostaglandin $F_{2 \alpha}$ and a synthetic progestagen ( $3 \mathrm{mg}$ Norgestomet) for 2 or 10 days on the first day of dominance of the second dominant follicle (DF2) of the oestrous cycle, to give a 4 day $(n=19 ; \mathrm{N} 2)$ or 12 day $(n=21 ; \mathrm{N} 10)$ duration of dominance of the dominant follicle at ovariectomy $18 \mathrm{~h}$ after implant removal and before the predicted gonadotrophin surge. Ultrasound scanning determined emergence of a new wave of follicles in five N10 heifers the day before $(n=1)$ or day of ovariectomy $(n=4)$ (N10-NonDom). Dominant follicles from the remaining N10 heifers (N10-Dom) were larger $(P<0.05)$ on the day of ovariectomy $(17.8 \pm 0.6 \mathrm{~mm})$ than those from N2 heifers $(13.6 \pm 0.4 \mathrm{~mm})$. The oestradiol:progesterone ratio of follicular fluid from N10-Dom heifers was reduced $(21.7 \pm 3.1$ versus $34.1 \pm 4.4 ; P<0.05)$, while inhibin A (as measured by immunoradiometric assay) was increased $\left(12.7 \pm 1.0\right.$ versus $\left.9.0 \pm 0.7 \mu \mathrm{g} \mathrm{ml}^{-1} ; P<0.05\right)$ compared with N2 heifers. Eleven of twelve N2 oocytes demonstrated nuclear activation without germinal vesicle breakdown, while seven of eight N10-Dom oocytes had undergone germinal vesicle breakdown and had progressed to metaphase I (6/8) or II $(1 / 8)$. In contrast to N2 oocytes, N10-Dom oocytes showed a larger perivitelline space containing more cumulus cell process endings, vacuoles, irregular vesicles, and more mitochrondia and lipid droplets throughout the ooplasm, yet the degree of cumulus cell expansion and atresia was similar. Thus, final oocyte maturation leading to metaphase I is initiated in most dominant follicles with a dominance period of $>9$ days before the gonadotrophin surge and is associated with a reduction in dominant follicle health. However, ovulatory ability is maintained and will lead to the ovulation of aged oocytes, markedly reducing subsequent pregnancy rates.

\section{Introduction}

The developmental competence of oocytes ovulated in vivo or used for in vitro fertilization is a key factor determining number and quality of embryos produced. However, the roles of the follicular and endocrine milieu in determining oocyte quality are not clear. LH is an important endocrine factor that regulates the fate of the dominant follicle in most physiological states in cattle (dominant follicle atresia is associated with slow LH pulse frequency; final maturation and ovulation of the dominant follicle is associated with rapid LH pulse frequency) (Rahe et al., 1980; Stock and Fortune, 1993). However, intermediate $\mathrm{LH}$ pulse frequencies (one pulse per 1-2 h), associated with subluteal concen-

Received 30 July 1998. trations of progesterone or treatment with synthetic progestagen after luteolysis, maintain the growth and oestradiol production of a dominant follicle, leading to an extension in its period of dominance (persistence) (Savio et al., 1993; Stock and Fortune, 1993; Taylor et al., 1993; Cooperative Regional Research Project, NE-161, 1996). Longterm persistent dominant follicles can still ovulate, resulting in normal corpus luteum formation, although pregnancy rates are significantly reduced (Sanchez et al., 1993; Savio et al., 1993; Mihm et al., 1994; Cooperative Regional Research Project, NE-161, 1996; Austin et al., 1998). Specifically, the duration of dominance of the ovulatory follicle is closely related to subsequent fertility, in that a short duration of dominance (1-4 days) results in pregnancy rates $>80 \%$, and long duration of dominance ( $>9$ days) results in abruptly decreasing pregnancy rates to $<20 \%$ (Mihm et al., 1994; 
Austin et al., 1998). Fertilization of the oocyte from persistent follicles is achieved although reduced cleavage rates and retarded early embryonic growth have been reported (Hill et al., 1971; Wishart, 1977; Ahmad et al., 1995).

Defects in early embryonic development up to the 8-16cell stages are generally attributed to perturbations within the ovulated oocyte (Ahmad et al., 1995), possibly caused by alterations in oocyte cytoplasmic maturation, that is its mRNA content or protein synthesis (Frei et al., 1989). As yet, only one report (Revah and Butler, 1996) has studied oocytes recovered from the persistent first dominant follicle of the ovarian cycle. Within those oocytes, dispersion of nuclear material in the ooplasm was observed, possibly indicating premature (before the gonadotrophin surge) germinal vesicle breakdown (GVBD). Therefore, it was proposed that the present study determine the cause of compromised early embryonic survival by (1) examining the exact nature of cytoplasmic or nuclear changes occurring in oocytes after long periods of follicle dominance, and (2) the characterization of the associated intrafollicular environment, as this may be causatively involved in altered oocyte meiotic activity (Smith et al., 1996). Enhanced progesterone synthesis was shown in persistent dominant follicles, indicating possible early luteinization, although dominant follicle oestradiol synthesis was unchanged (Revah and Butler, 1996; Bigelow and Fortune, 1998). Conversely, gradual atresia of persistent dominant follicles may contribute to the compromised developmental competence of oocytes (Ahmad et al., 1995). In this respect, intrafollicular concentrations of growth factors, such as the inhibin-activin family, have been used to estimate the fate of follicles (dominance, atresia or luteinization) (Guilbault et al., 1993; Sunderland et al., 1996; Mihm et al., 1997), and have also been shown to influence oocyte and embryo development in vitro (Alak et al., 1996; Stock et al., 1997; Silva and Knight, 1998). Therefore, the aims of this study were to (1) clarify the exact cytoplasmic and nuclear status of oocytes recovered from dominant follicles able to ovulate, yet with a duration of dominance of $>9$ days (associated with low fertility), and (2) associate the maturational status of the oocyte with intrafollicular markers of follicle health (oestrogenic activity and inhibin A), functional dominance of its respective follicle, and the systemic gonadotrophin and steroid environment. A model was used that (1) controls the duration of dominance (which is related directly to subsequent fertility) of the persistent and control dominant follicle in a very precise manner, and (2) allows the recovery of control or persistent oocytes in the same phase of the cycle (the early follicular phase) but before the predicted time of the gonadotrophin surge (Mihm et al., 1994; Austin et al., 1998).

\section{Materials and Methods}

\section{Animals and treatments}

Crossbred beef heifers $(406.3 \pm 3.7 \mathrm{~kg}$; approximately 1.5 years old) were housed on straw and had ad libitum access to grass silage and water, supplemented each day with $2 \mathrm{~kg}$ of a $16 \%$ crude protein concentrate per heifer. Heifers were given two i.m. injections of $15 \mathrm{mg}$ Luprostiol, a prostaglandin $\mathrm{F}_{2 \alpha}{ }^{-}$ analogue (Prosolvin ${ }^{\circledast}$, Intervet UK Ltd, Cambridge), 11 days apart to synchronize oestrus (day 0 ). Observations for the onset of oestrus, commencing $36 \mathrm{~h}$ after the second $\mathrm{PGF}_{2 \alpha}$ injection, were carried out four times per day. On the first day of dominance of the second dominant follicle (DF2) (defined by ultrasound; see below), heifers received a single i.m. injection of $\mathrm{PGF}_{2 x}$ and a subcutaneous ear implant of $3 \mathrm{mg}$ synthetic progestagen, Norgestomet (Crestar ${ }^{(0)}$, Intervet UK Ltd) for either 2 days (N2; $n=19)$ or 10 days (N10; $n=21$ ), to achieve either a short (4 days) or long (12 days) duration of dominance of the preovulatory follicle, which, after ovulation and artificial insemination, are known to result in high $(>80 \%)$ or low $(<20 \%)$ pregnancy rates, respectively (Mihm et al., 1994).

\section{Ultrasound examination of ovaries and ovariectomies}

From day 5 of the oestrous cycle until ovariectomy, the growth and regression of individual follicles $>4 \mathrm{~mm}$ were monitored each day by ultrasonography using a real-time, B-mode, linear array ultrasound scanner with a $7.5 \mathrm{MHz}$ intrarectal transducer (Dynamic Imaging, Concept 500, Livingston). The day of emergence of a new follicle wave was defined as the day when the first member of the cohort, from which the new dominant follicle was selected, reached $6 \mathrm{~mm}$ in diameter. The first day of dominance of DF2 was defined by all three of the following morphological criteria: (1) the first day that all subordinate follicles had stopped increasing in diameter, that is, were static or regressing; (2) the difference in size between the dominant follicle and the next largest (subordinate) follicle was $>2 \mathrm{~mm}$; (3) the dominant follicle had achieved a minimum diameter of $9 \mathrm{~mm}$. The duration of dominance of the DF2 at ovariectomy was defined as the interval in days between the first day of dominance of the DF2, which was counted as day 1 , and the day of ovariectomy.

Eighteen hours after removal of the implant, the ovary bearing the DF2 was removed by transvaginal colpotomy (Drost et al., 1992). Immediately after ovariectomy, the ovary was placed on ice, the DF2 was dissected and measured, its follicular fluid aspirated and stored at $-20^{\circ} \mathrm{C}$ for subsequent hormone analysis. Oocytes were recovered either from follicular fluid or after flushing the antral cavity with $0.1 \mathrm{~mol} \mathrm{PBS} \mathrm{1}^{-1}$. The time of ovariectomy was chosen to be before the expected onset of oestrus and the preovulatory gonadotrophin surge, as heifers treated identically had an onset of oestrus $34-48 \mathrm{~h}$ after withdrawal of the implant (Mihm et al., 1994; Austin et al., 1998). All animal experimentation was performed in compliance with regulations set down by the BioMedical Centre, University College Dublin, and the Cruelty to Animals Act (Ireland), 1897.

\section{Collection of blood samples}

Blood samples were collected each day via jugular venepuncture ( $10 \mathrm{ml}$ into evacuated glass containers) on the 
first day of dominance of DF2 and for 3 more days to monitor the decrease in progesterone concentrations after $\mathrm{PGF}_{2 \alpha}$ injection, and until ovariectomy to establish circulatory concentrations of both oestradiol and FSH. Blood samples were collected from N2 and N10 heifers $(n=6)$ every $15 \mathrm{~min}$ for $6 \mathrm{~h}$ on the first day of dominance of DF2, before PGF $_{2 \alpha}$ injection and implant insertion, and subsequently at 2 or 3 day intervals until implant removal, and for $4 \mathrm{~h}$ before ovariectomy (days 1, 3 and 4 of dominance of DF2 in N2 heifers, and days $1,3,6,9,11$ and 12 of dominance of DF2 in N10 heifers) to determine LH pulse characteristics during exogenous progestagen treatment. Concentrations of $\mathrm{LH}$ were determined in single blood samples collected in all N2 and N10 heifers on the day of implant removal and ovariectomy to monitor for the occurrence of an early onset of the LH surge. Each blood sample was maintained at room temperature for $1 \mathrm{~h}$ after collection, at $4^{\circ} \mathrm{C}$ overnight, and centrifuged at $700 \mathrm{~g}$ for $20 \mathrm{~min}$. The serum was stored at $-20^{\circ} \mathrm{C}$ until determination of hormone concentrations.

\section{Hormone assays}

Gonadotrophins. Serum LH concentrations were determined by radioimmunoassay (Cooke et al., 1997) using a monocional LH antibody (518B7 anti-LH at 1:150000 dilution; supplied by J. Roser, University of California, Davis, CA), an ovine LH standard (NIAMDD-oLH-24, NIH, Rockville, MD) and an ovine radio-iodinated LH tracer (Matteri et al., 1987). The sensitivity of the LH assay was $0.6 \mathrm{ng} \mathrm{ml}^{-1}$ and the mean intraand interassay coefficients of variation for two serum samples containing 2.4 and $22.3 \mathrm{ng} \mathrm{LH} \mathrm{ml}^{-1}$ were 17.7 and $13.1 \%(n=4)$ and 21 and $17.8 \% \quad(n=19)$, respectively. Serum FSH concentrations were quantified using a heterologous assay that had been validated by Crowe et al. (1997), with the NIDDK-anti-oFSH antibody (AFP-C 5288113), an ovine tracer and a bovine FSH standard preparation (USDA B1 bFSH). The sensitivity of this assay was $1.6 \mathrm{ng} \mathrm{ml}^{-1}$, and the intra- and interassay coefficients of variation for three serum samples containing 18.1, 27.8 and $46.8 \mathrm{ng} \mathrm{ml}^{-1} \mathrm{FSH}$ were 8.2, 11.5 and $6.4 \%(n=4-6)$ and $9.4,18.3$ and $4.4 \%(n=3)$, respectively.

Steroid hormones. Concentrations of oestradiol in serum and follicular fluid (1:500-2000 dilution in assay buffer) were estimated using a validated radioimmunoassay (Prendiville et al., 1995). The sensitivity of this assay was $0.2 \mathrm{pg} \mathrm{ml}^{-1}$, and the intra- and interassay coefficients of variation for two serum pools containing 0.4 and $7.5 \mathrm{pg} \mathrm{ml}^{-1}$ oestradiol were 16.7 and $10.8 \%(n=2-6)$ and 20.7 and $6.2 \%(n=4)$. All follicular fluid samples were analysed within one assay with an intra-assay coefficient of variation of $15.9 \%(n=6)$ for one follicular fluid sample containing $3.8 \mathrm{pg}$ of oestradiol per tube.

Concentrations of progesterone in serum and follicular fluid (1:50-100 dilution in assay buffer) were estimated using a validated radioimmunoassay (Ronayne and Hynes, 1990). The sensitivity of this assay was $0.05 \mathrm{ng} \mathrm{ml}^{-1}$, and the mean intra- and interassay coefficients of variation for three serum pools containing $0.2,0.8$ and $2.7 \mathrm{ng} \mathrm{ml}^{-1}$ progesterone were
$12.8,5.2$ and $12.8 \%(n=4-6)$ and $5.1,4.6$ and $7.6 \%(n=3)$. The progesterone radioimmunoassay shows no crossreaction with the Norgestomet released by the progestagen implants (Mihm et al., 1994; Manikkam and Rajamahendran, 1997). All follicular fluid samples were analysed within one assay with an intra-assay coefficient of variation of $13.6 \%(n=6)$ for one follicular fluid sample containing $5.8 \mathrm{pg}$ progesterone per tube.

The ratio of oestradiol and progesterone concentrations in follicular fluid was used to determine the oestrogen activity, which can be used as a measure of follicular health; oestrogen active (EA; oestradiol:progesterone $>1$ ) follicles are predicted to be healthy and oestrogen inactive (oestradiol: progesterone $<1$ ) follicles are considered atretic (Ireland and Roche, 1983).

Inhibin radioimmunoassay in follicular fluid. Immunoreactive $\alpha$-inhibin in the follicular fluid of individual follicles was measured using a validated radioimmunoassay (Knight $e t$ al., 1989; Sunderland et al., 1996). Each tube analysed contained $0.02 \mu \mathrm{l}$ follicular fluid. All samples were analysed in one assay with a sensitivity of $0.1 \mathrm{ng}$ per tube; the intraassay coefficients of variation for two samples of 0.7 and 1.8 ng per tube were 21.1 and $10.3 \%$, respectively $(n=8)$. Since free $\alpha$ subunits and dimeric inhibin forms crossreact with the S114/2-hINH $\alpha$ C1-32 antiserum in a parallel fashion, results are referred to hereafter as total $\alpha$-inhibin immunoactivity.

Inhibin immunoradiometric assay in follicular fluid. Concentrations of inhibin $\mathrm{A}$ in follicular fluid were measured using a validated two-site immunoradiometric assay (IRMA; Knight and Muttukrishna, 1994; Sunderland et al., 1996). Each tube analysed contained $0.1 \mu \mathrm{l}$ follicular fluid. The detection limit was $0.2 \mathrm{ng}$ per tube and the intra-assay coefficients of variation for two follicular fluid samples of 1.4 and $3.2 \mathrm{ng}$ per tube were 9.6 and $5.8 \%$, respectively ( $n=10$; all samples were analysed in one assay). Unlike the radioimmunoassay, the immunoradiometric asaay shows no crossreaction with pro- $\alpha \mathrm{C}$. A high correlation is seen between concentrations of inhibin A detected by IRMA and the amounts of the 32-34 $\mathrm{kDa}$ molecular mass form of dimeric inhibin detected by western blotting in follicular fluid (Sunderland et al., 1996).

\section{Processing of oocytes}

Recovered oocytes were fixed, embedded and sectioned as described by Hyttel and Madsen (1987), with the following modifications. Subsequent to dropping oocytes in agar, agar cubes were post-fixed in $1 \%(\mathrm{w} / \mathrm{v})$ osmium tetroxide in cacodylate buffer for $1 \mathrm{~h}$ at room temperature. A $15 \mathrm{~min}$ wash in distilled water followed, after which agar cubes with oocytes were dehydrated in 30,60, 90 and $100 \%$ ethanol in distilled water (with solution changes every $15 \mathrm{~min}$ ). Alcohol was removed by washing in propylene oxide:ethanol (1:1), and in $100 \%$ propylene oxide. Agar cubes were exposed to increasing concentrations of the epoxy resin $(25,50$ and $75 \%$ in propylene oxide) until immersion in $100 \%$ unaccelerated resin (araldite My 753, Bio-Rad Microscience Division, 
Maylands Avenue, Hemel Hempstead; with the hardeners, methyl nadic anhydride and dodecenyl succinic anhydride at 53:35:12) and, finally, the accelerated resin (accelerator: 3\% $\mathrm{N}$-benzyl, $\mathrm{N}$-N-dimethylamine). Capsules containing the agar cube with the oocyte in the accelerated resin were kept at $60^{\circ} \mathrm{C}$ for 2 days. Cured blocks were trimmed and the oocytes cut into semi-thin sections $(1-2 \mu \mathrm{m})$ using $45^{\circ}$ glass knives. Every second or third section was collected on uncoated slides (30-45 sections per oocyte), sections were stained with toluidine blue and coverslips were mounted with immersion oil for light microscopic examination of sections $(\times 200)$.

\section{Evaluation of oocytes}

The degree of cumulus cell expansion, indicated by the shape of adjoining cumulus cells and their contact with each other and the zona pellucida, was scored from 0 (not expanded) to 3 (fully expanded) independently by two people using established techniques (Hyttel et al., 1987, 1997; Assey et al., 1993). Similarly, the occurrence of nuclear (pyknosis) and cytoplasmic changes (granulation and vesiculation) within the cumulus cells indicative of cell death was scored from 0 (healthy) to 3 (degenerate). The frequency of visible cumulus cell process endings within the perivitelline space (PVS) was scored from 0 (absent) to 3 (present in large numbers), and the size of the PVS was scored as 0 (absent), or 1 to 3 (small to large). The abundance and spatial distribution of mitochondria, lipid droplets and vesicles visible within the cytoplasm, as well as their association with other cell organelles, were determined on an equatorial section of each oocyte according to established techniques (Hyttel et al., 1987, 1997; Assey et al., 1993). The abundance of organelles was scored from 0 (absent) to 3 (very frequent) and the characteristic distribution within the cytoplasm (peripheral or central, diffuse or in clusters, associated with other organelles) was assessed for each oocyte. Oocyte nuclear morphology was evaluated on appropriate semi-thin sections according to established techniques (Hyttel et al., 1987, 1997; Assey et al., 1993), and stages in the nuclear development can be summarized as follows (Assey et al., 1993; Hyttel et al., 1997): (1) The oocyte nucleus I stage (germinal vesicle stage) is characterized by a spherical nucleus located peripherally in the ooplasm, which identifies the immature, meiotically arrested oocyte. (2) The nucleus in the oocyte nucleus II stage demonstrates slight to heavy undulations of the nuclear envelope, representing nuclear activation. This stage precedes the dissolution of the nuclear membrane and chromatin condensation during GVBD. (3) Metaphase chromosomes aligned in the ooplasm characterize the metaphase I stage. (4) The metaphase II stage is characterized by the presence of an extruded first polar body, and chromosomes present in the ooplasm and polar body. Metaphase I and II subsequent to GVBD are indicative of final nuclear maturation.

\section{Statistical analyses}

Two of the N10 heifers (from one of which blood samples were collected intensively for identification of $\mathrm{LH}$ pulses) were excluded from all data analysis, as one heifer ovulated the day before implant removal, and the other had developed a new dominant follicle on the day of implant removal with continuous dominant follicle turnover thereafter. Analysis of ultrasound data from the remaining N10 heifers led to the distinction between those in which DF2 appeared to be dominant (no other follicle growth) up to the time of ovariectomy (N10-Dom; $n=14)$, and those in which emergence of a new follicle wave was detected either on the day of implant removal or ovariectomy (N10NonDom; $n=5$ ). These two N10 groups are considered separately for the analysis of DF2 growth, FSH and oestradiol serum concentrations, follicular fluid and oocyte data.

Data relating to the second follicle wave were analysed by one-way analysis of variance. Serum hormone concentrations were subjected to one-way analysis of variance or repeated measures analysis of variance. The characteristics of LH secretion at different times during the period of dominance of DF2 were determined using a modified Pulsar software (PC Pulsar), as outlined by Merriam and Wachter (1982, 1984). Constant, linear and quadratic components used to describe the overall assay standard deviation were $34.8,8.6$ and 0.032 , respectively. Smoothing time was set at $300 \mathrm{~min}$, and the cut-off values for peak detection were 1.5 for G1, and 0.4 for G2-G5. Parameters relating to the pulsatile $\mathrm{LH}$ secretion were compared at different times during the period of dominance of DF2 within treatments (N2 or N10), using repeated measures analysis of variance. Repeated measures analysis of variance revealed no differences in any of the LH pulse parameters between N10-Dom $(n=3)$ and N10-NonDom $(n=2)$ heifers; thus, LH data were pooled for all five N10 heifers.

Data relating to follicle size, volume or intrafollicular hormone concentrations were analysed using one-way analysis of variance or Student's $t$ test. The comparisons were made among DF2 recovered from N2, N10-Dom and N10-NonDom heifers, and between oocytes from DF2 before or after GVBD. Hormonal data were transformed to logarithmic values before statistical analysis, if Bartlett's test or Student's $t$ test showed significant differences between standard deviations, but are presented as arithmetic means \pm SEM for clarity.

The characteristics of cumulus cells, and cytoplasmic and nuclear structures of the oocyte were analysed by chisquared analysis in the case of proportional data, whereas mean scores underwent one-way analysis of variance.

The number of heifers contributing to ultrasound, hormonal, follicular fluid and oocyte data is indicated as appropriate. In one of the N2 heifers, a second follicle wave emerged without subsequent selection of a new dominant follicle; this animal received the synthetic progestagen implant on the first day of dominance of the next dominant follicle (selected after emergence of a third follicle wave) and, from this animal, only the oocyte and follicular fluid data are included in the analysis. Blood samples could not be collected from one N10-Dom heifer; however, the ultrasound, follicular fluid and oocyte data from this animal are included in the analysis. 
Table 1. Characterization of LH secretion (mean \pm SEM) in heifers after selection and during growth of the second dominant follicle of the cycle maintained exogenously for a short (N2) or long (N10) period of dominance

\begin{tabular}{|c|c|c|c|c|c|c|c|c|c|}
\hline \multirow[b]{2}{*}{ LH } & \multicolumn{3}{|c|}{$\begin{array}{c}\mathrm{N} 2^{*} \\
\text { Day of dominance }\end{array}$} & \multicolumn{6}{|c|}{$\begin{array}{c}\mathrm{N} 10^{+} \\
\text {Day of dominance }\end{array}$} \\
\hline & 1 & 3 & $4(\mathrm{FP})$ & 1 & 3 & 6 & 9 & 11 & $12(\mathrm{FP})$ \\
\hline \multicolumn{10}{|l|}{ Concentrations per sampling period } \\
\hline Mean (ng ml-1 $)$ & $2.0 \pm 0.3^{a}$ & $2.5 \pm 0.3^{\text {ab }}$ & $3.0 \pm 0.4^{\mathrm{b}}$ & $Y .4 \pm 0.2^{a}$ & $1.8 \pm 0.2^{\mathrm{a}}$ & $1.9 \pm 0.3^{3 \mathrm{ab}}$ & $1.7 \pm 0.1^{\circ}$ & $2.0 \pm 0.3^{3 \mathrm{ab}}$ & $2.5 \pm 0.4^{\mathrm{b}}$ \\
\hline Basal (ng ml-1) & $1.7 \pm 0.2^{\mathrm{a}}$ & $1.7 \pm 0.2^{a}$ & $2.6 \pm 0.2^{b}$ & $1.0 \pm 0.1^{\wedge}$ & $1.3 \pm 0.3^{\mathrm{ab}}$ & $1.4 \pm 0.1^{\mathrm{ab}}$ & $1.3 \pm 0.1^{\prime \prime}$ & $1.6 \pm 0.2^{\mathrm{ab}}$ & $2.1 \pm 0.4^{\mathrm{b}}$ \\
\hline \multicolumn{10}{|l|}{ Pulse characteristics } \\
\hline Frequency (number of & $2.5 \pm 0.3^{a}$ & $3.2 \pm 0.5^{\prime \prime}$ & $3.0 \pm 0.4^{\mathrm{a}}$ & $2.4 \pm 0.5^{a}$ & $3.8 \pm 0.6^{\mathrm{b}}$ & $3.0 \pm 0.3^{\mathrm{ab}}$ & $3.4 \pm 0.3^{\text {ab }}$ & $3.0 \pm 0.6^{\mathrm{ab}}$ & $3.0 \pm 0$. \\
\hline Amplitude $\left(\mathrm{ng} \mathrm{ml}^{-1}\right)$ & $1.7 \pm 0.4^{a}$ & $2.7 \pm 1.1^{a}$ & $1.6 \pm 0.3^{a}$ & $1.5 \pm 0.4^{\mathrm{a}}$ & $1.6 \pm 0.2^{a}$ & $1.9 \pm 0.8^{n}$ & $1.2 \pm 0.3^{a}$ & $1.6 \pm 0.3^{a}$ & $1.9 \pm 0.4^{\mathrm{a}}$ \\
\hline
\end{tabular}

${ }^{*}$ Heifers were treated with prostaglandin and a synthetic progestagen ear implant for either 2 days $(\mathrm{N} 2 ; n=6)$ or 10 days $(\mathrm{N} 10 ; n=5)$, starting on the first day of dominance of the second dominant follicle (DF2) (mean day of the cycle = day 14). In two of the five N10 heifers, emergence of a new follicle was detected on the day of ovariectomy (day 12 of dominance).

'Blood samples were collected every $15 \mathrm{~min}$ for 6 or $4 \mathrm{~h}$ (follicular phase; FP) on respective days of dominance of DF2 starting on day 1 before implant insertion, continuing every 2 or 3 days until implant withdrawal (days 3 and 11 of dominance of DF2 for N2 and N10 heifers, respectively), and 1 day later on the day of ovariectomy.

Means with different superscripts within rows and within treatments are significantly different $(P<0.05)$.

\section{Results}

\section{Progesterone and LH pulse characteristics}

Serum progesterone concentrations declined $(P<0.05)$ from $2.8 \mathrm{ng} \mathrm{ml}^{-1}$ to $<0.5 \mathrm{ng} \mathrm{ml}^{-1} 1$ day after $\mathrm{PGF}_{2 \alpha}$ administration in both $\mathrm{N} 2$ and N10 heifers, and remained low thereafter. Mean and baseline $\mathrm{LH}$ concentrations increased $(P<0.05)$ between the luteal phase (day 1 of dominance of $\mathrm{DF} 2$ before $\mathrm{PGF}_{2 \alpha}$ administration and implant insertion) and the follicular phase (one day after implant removal) in both $\mathrm{N} 2$ and N10 heifers (Table 1). The number of $\mathrm{LH}$ pulses per $6 \mathrm{~h}$ sampling period increased in N10 heifers 2 days after $\mathrm{PGF}_{2 \alpha}$ administration and progestagen implant insertion $(P<0.05)$ from one pulse every $2.5 \mathrm{~h}$ to one pulse every $1.6 \mathrm{~h}$. No significant differences were detected in the pulse amplitude among days or treatments (Table 1). None of the heifers sampled intensively during the last $6 \mathrm{~h}$ of the progestagen implant or $14 \mathrm{~h}$ later (that is, before ovariectomy) demonstrated an increase in LH concentrations indicative of the occurrence of a gonadotrophin surge, and LH was not increased to surge concentrations in any of the blood samples collected from heifers before implant removal or ovariectomy (data not shown).

\section{Follicular dynamics and serum FSH and oestradiol concentrations}

The characteristics of the second follicle wave up to attainment of dominance of DF2 did not differ $(P>0.05)$ between N2 and N10 heifers; the second wave emerged on days $10.6 \pm 0.6$ and $10.2 \pm 0.3$ of the cycle, and the first days of dominance of DF2 were day $14.1 \pm 0.5$ and $13.8 \pm 0.4$ in N2 and N10 heifers, respectively. Subsequent to treatment, DF2 grew from $10.1 \pm 0.2,10.2 \pm 0.2$ and $10.6 \pm 0.7 \mathrm{~mm}$ to $13.6 \pm$ $0.4,17.8 \pm 0.6$ and $16.8 \pm 1.2 \mathrm{~mm}$ in N2, N10-Dom and N10NonDom heifers, respectively $(P<0.05)$ (Fig. $1 \mathrm{a}, \mathrm{c}, \mathrm{e})$. No other follicle growth before ovariectomy was detected in any $\mathrm{N} 2$ heifers or in 14/19 N10 heifers (N10-Dom), resulting in a duration of functional dominance of DF2 at ovariectomy of $4.4 \pm 0.2$ and $12.4 \pm 0.3$ days in N2 and N10-Dom heifers, respectively $(P<0.05)$.

Serum oestradiol increased from the day of $\mathrm{PGF}_{2 \alpha}$ administration and implant insertion, with higher $(P<0.05)$ concentrations on the day of ovariectomy in N10-Dom (5.6 \pm $0.9 \mathrm{pg} \mathrm{ml}^{-1}$ ) than in $\mathrm{N} 2$ heifers $\left(4.2 \pm 0.3 \mathrm{pg} \mathrm{ml}^{-1}\right)$, while FSH remained at basal concentrations in both groups of heifers (Fig. 1b,d).

In the remaining five N10 heifers (N10-NonDom), emergence of a new follicle wave was detected by ultrasound on either the day of implant removal $(n=1)$ or on the day of ovariectomy $(n=4)$. In these heifers, serum oestradiol increased to day 5 of dominance, decreased abruptly $(P<0.05)$ and remained low until the day of implant removal (Fig. 1f). In contrast, FSH concentrations increased $(P<0.05)$ from $21.3 \pm 1.0 \mathrm{ng} \mathrm{ml}^{-1}$ on day 5 of dominance to $38.5 \pm 7.0 \mathrm{ng} \mathrm{m}^{-1}$ on the day of implant removal (Fig. 1f).

\section{Concentrations of steroids and inhibins in follicular fluid}

Persistent DF2s recovered from N10-Dom heifers were 5 $\mathrm{mm}$ larger, yet had a $35 \%$ lower oestradiol:progesterone ratio, and $40 \%$ higher inhibin $A$ concentrations $(P<0.05)$ in follicular fluid than did N2 DF2s (Table 2). Persistent DF2s recovered from N10-NonDom had decreased intrafollicular oestradiol and increased inhibin A concentrations compared with both N2 and N10-Dom DF2s $(P<0.05)$. Intrafollicular concentrations of progesterone and total $\alpha$-inhibin immunoreactivity were similar in the three follicle groups $(P>0.05)$ (Table 2).

\section{Oocyte evaluation}

Oocyte recovery and cumulus cells. Of 31 oocytes recovered, eight were damaged during preparation or sectioning and, 

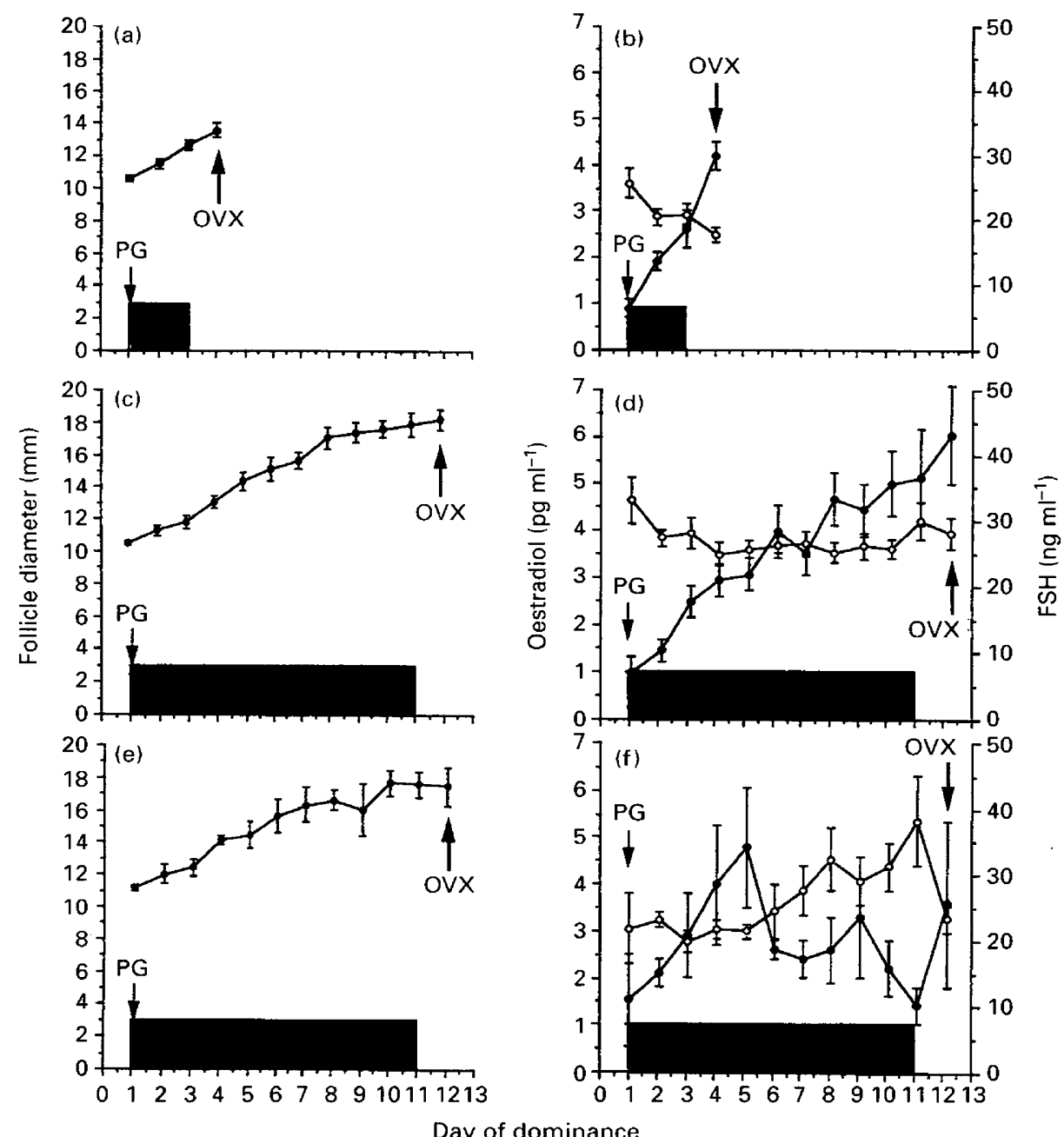

Fig. 1. Growth of the second dominant follicle $(a, c, e)$ and changes in serum oestradiol $(\bullet)$ and FSH $(O)$ concentrations (mean \pm SEM) $(b, d, f)$ in heifers treated with prostaglandin $F_{2 \alpha}(P G)$ and a synthetic progestagen $(\square)$ for $2(\mathrm{~N} 2 ; n=18$; a,b) or 10 days $(\mathrm{N} 10, \mathrm{c}-\mathrm{f})$ with (N10-Dom; $n=13-14$ ) or without maintained dominance (N10-NonDom; $n=5$ ). Therefore (c) and (d) depict follicle and hormone parameters established for N10-Dom, and (e) and (f) depict follicle and hormone parameters established for N10-NonDom heifers. The time of ovariectomy (OVX) is indicated by arrows.

consequently, $12 \mathrm{~N} 2$, eight N10-Dom and three N10NonDom oocytes were evaluated. Subsequent to oocyte aspiration, one $\mathrm{N} 2$ and two N10-Dom oocytes were denuded, and the remaining N2, N10-Dom and N10NonDom oocytes showed a similar $(P>0.05)$ degree of cumulus expansion (scored $0.8 \pm 0.2,0.4 \pm 0.2,0.6 \pm 0.2$ ) and atresia (scored $0.8 \pm 0.1,1.2 \pm 0.3,1.2 \pm 0.5$ ), respectively, in cumulus cells. However, more $(P<0.05)$ cumulus cell process endings (scored $1.8 \pm 0.3$ versus $1.1 \pm 0.1$ ) were detected in N10-Dom than in N2 oocytes, within a larger perivitelline space in N10-Dom and N10-NonDom (scored $2.3 \pm 0.3$ and 2.0 ) than in N2 oocytes (scored $1.1 \pm 0.3$ ) (Fig. $2 a, b)$.

Nuclear morphology. Eleven of twelve N2 oocytes demonstrated an undulating nuclear envelope containing heterochromatin (10/11 oocytes) and one or two nucleoli (8/11 oocytes) in oocyte nucleus stage II before GVBD (Table 3$)$; $50 \%$ of nucleoli showed vacuolization (Fig. 2c). A polar body showing chromosomes was detected in one N2 oocyte, indicating GVBD and its progression to metaphase II (Table 3; Fig. 2e). In contrast, only one of eight N10-Dom oocytes was before GVBD in oocyte nucleus stage II (showing vacuolated nucleoli), while the remainder had undergone GVBD and progressed to metaphase I (6/8) or II (1/8) (Table 3; Fig. 2 b,d). Of the three oocytes recovered from N10-NonDom heifers, one oocyte was classified to be before GVBD in oocyte nucleus stage II, whereas the other two had undergone GVBD and were at metaphase I.

Cytoplasmic morphology. In general, changes in cytoplasmic morphology were closely related to nuclear maturation, and 
Table 2. Follicle size and intrafollicular steroid and inhibin concentrations (mean \pm SEM) of heifer preovulatory follicles with a short (N2) or long period of dominance and which had maintained (N10-Dom) or lost dominance (N10-NonDom $)^{1}$

\begin{tabular}{|c|c|c|c|}
\hline Follicle characteristics & $\mathrm{N} 2(n=15)$ & N10-Dom $(n=12-14)$ & N10-NonDom ${ }^{2}(n=4-5)$ \\
\hline Diameter $(\mathrm{mm})^{1}$ & $15.1 \pm 0.3^{\mathrm{a}}$ & $19.9 \pm 0.6^{\mathrm{b}}$ & $16.4 \pm 1.4^{\mathrm{a}}$ \\
\hline Volume (ml) & $1.6 \pm 0.1^{a}$ & $3.8 \pm 0.4^{\mathrm{b}}$ & $2.6 \pm 0.6^{\mathrm{a}}$ \\
\hline Oestradiol (E) & $466.8 \pm 19.2^{\mathrm{a}}$ & $428.5 \pm 44.6^{\mathrm{a}}$ & $242.6 \pm 68.6^{b}$ \\
\hline Progesterone $(\mathrm{P})$ & $16.4 \pm 1.8^{\mathrm{a}}$ & $24.6 \pm 4.6^{\mathrm{a}}$ & $19.1 \pm 3.0^{\mathrm{a}}$ \\
\hline Oestrogen activity (E:P) & $34.1 \pm 4.4^{\mathrm{a}}$ & $21.7 \pm 3.1^{\mathrm{b}}$ & $13.4 \pm 4.3^{\mathrm{b}}$ \\
\hline Dimeric inhibin-A (IRMA) & $9.0 \pm 0.7^{a}$ & $12.7 \pm 1.0^{\mathrm{b}}$ & $20.0 \pm 2.2^{c}$ \\
\hline
\end{tabular}

${ }^{1}$ Heifers were treated with prostaglandin and a synthetic progestagen ear implant for either 2 days (N2) or 10 days (N10) starting on the first day of dominance of the second dominant follicle (DF2) (mean day of the cycle = day 14). Follicles were recovered at ovariectomy $18 \mathrm{~h}$ after implant withdrawal. Follicles were measured after dissection from ovaries.

${ }^{2}$ In five N10 heifers, emergence of a new wave was detected on the day of implant removal or ovariectomy (N10-NonDom). RIA, radioimmunoassay; IRMA, immunoradiometric assay.

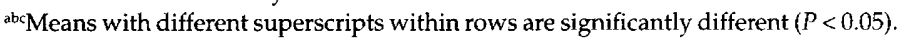

followed the descriptions of final oocyte maturation outlined in Assey et al. (1993) and Hyttel et al. (1997). No asynchrony between nuclear maturation and changes in cytoplasmic morphology was seen. Oocytes in the oocyte nucleus stage II (recovered from 11/12 N2, 1/8 N10-Dom and 1/3 N10NonDom DF2) had peripherally located mitochondria in large clusters associated with lipid droplets; large, evensized vesicles were distributed diffusely throughout the ooplasm (Table 4; Fig. 2a). In contrast, oocytes after GVBD (recovered from $1 / 12 \mathrm{~N} 2,7 / 8$ N10-Dom and 2/3 N10NonDom DF2) demonstrated a diffuse distribution of mitochondria throughout most of the ooplasm, with no close association with lipid droplets; the vesicle size varied from small to confluent and large. Vacuoles were visible centrally in $50 \%$ of N10-Dom oocytes (Table 4; Fig. 2b).

Characteristics of follicles the oocytes of which were classified to be either before or after germinal vesicle breakdown. Retrospective reclassification showed that DF2s from which oocytes before GVBD were recovered were of a smaller size $(15.7 \pm 0.6$ versus $19.7 \pm 0.4 \mathrm{~mm} ; P<0.05)$, had a smaller follicular fluid volume $(2.0 \pm 0.4$ versus $3.5 \pm 0.2 \mathrm{ml} ; P<0.05)$, a higher oestradiol concentration $(465.4 \pm 23.6$ versus $382.6 \pm 74.6 \mathrm{ng}$ $\left.\mathrm{ml}^{-1} ; P<0.05\right)$, and a higher oestradiol:progesterone ratio $(37.0 \pm 5.3$ versus $21.8 \pm 5.1 ; P=0.07)$ compared with follicles in which oocytes had undergone GVBD and progressed to metaphase I or II. Despite similar total $\alpha$-inhibin immunoactivity, the concentration of inhibin $A$ in follicular fluid was increased $(P<0.05)$ in follicles with metaphase oocytes compared with those with oocytes before GVBD (14.2 \pm 1.7 versus $9.4 \pm 0.7 \mu \mathrm{g} \mathrm{ml}^{-1}$ ).

\section{Discussion}

This study is unique in that it relates cytoplasmic and nuclear morphological changes occurring in oocytes recovered from dominant follicles in the early follicular phase (and thus likely to ovulate) and with a period of dominance $>9$ days (associated with markedly reduced pregnancy rates) to intrafollicular steroid and inhibin A concentrations, which are a measure of follicle health (Badinga et al., 1992; Guilbault et al., 1993; Ireland et al., 1994; Sunderland et al., 1996; Mihm et al., 1997). The results demonstrate that: (1) all except one oocyte recovered from follicles that were dominant for 12 days had initiated final oocyte maturation before the expected endogenous $\mathrm{LH}$ surge, in contrast to oocytes recovered from follicles that were dominant for 4 days; (2) final oocyte maturation occurred synchronously in cytoplasm and nucleus; (3) oocyte and follicular maturation were asynchronous, as little cumulus cell expansion occurred despite GVBD, and follicles did not demonstrate changes in steroidogenesis and inhibin A indicative of luteinization (Sunderland et al., 1996; Bigelow and Fortune, 1998); and (4) persistent follicles demonstrated intrafollicular alterations in steroidogenesis and inhibin A, which may precede the onset of atresia (Guilbault et al., 1993; Ireland et al., 1994; Sunderland et al., 1996). In addition, $50 \%$ of oocytes recovered from persistent dominant follicles had large vacuoles, indicating possible degenerative changes within the ooplasm.

Germinal vesicle breakdown was accompanied by retraction of cumulus cell process endings and a reorganization of intracellular organelles characteristic of resumption of meiosis in dominant follicles after the gonadotrophin surge (Assey et al., 1993). However, in the present study, oocytes were recovered approximately $18 \mathrm{~h}$ before the expected endogenous LH surge (Mihm et al., 1994; Austin et al., 1998). This finding was confirmed by the fact that serum LH concentrations did not show an increase indicative of the surge, and none of the follicular fluid samples showed the increase in progesterone and total $\alpha$ inhibin immunoreactivity typical for follicular fluid samples recovered from luteinizing preovulatory follicles after the LH surge (Sunderland et al., 1996). Eleven of twelve oocytes recovered from dominant follicles in the early follicular phase that were dominant for 4 days (present study) had not undergone GVBD, but demonstrated an undulating 

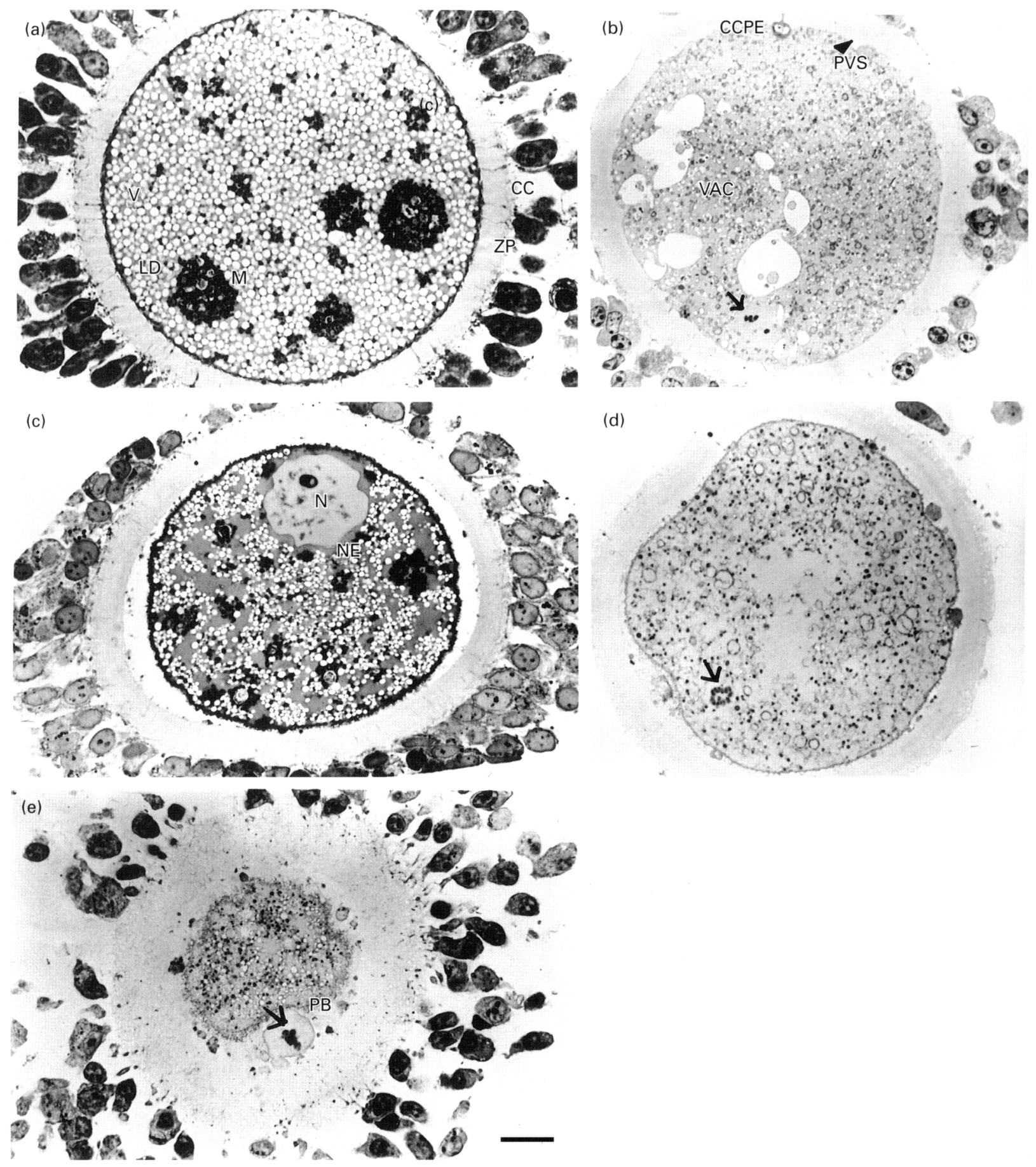

Fig. 2. (a) Oocyte recovered from a preovulatory follicle on day 4 of dominance (N2), obtained $18 \mathrm{~h}$ after implant removal (follicular phase) in heifers treated with prostaglandin $\mathrm{F}_{2 \alpha}$ and a synthetic progestagen for 2 (N2; $\left.n=18 ; \mathrm{a}, \mathrm{b}\right)$ or 10 days (N10, c-e) with (N10Dom; $n=13-14$ ) or without maintained dominance (N10-NonDom; $n=5$ ). CC, cumulus cells; $Z P$, zona pellucida; $V$, vesicles; $M$, mitochondria; LD, lipid droplets. (b) Oocyte recovered from a preovulatory follicle on day 12 of dominance with maintained dominance (N10-Dom), obtained $18 \mathrm{~h}$ after implant removal (follicular phase), and assigned to metaphase I. PVS, perivitelline space (arrowhead); CCPE, cytoplasmic cell process ending. Chromosomes (arrow) and large vacuoles (VAC) are visible in the ooplasm. (c) Oocyte recovered from a preovulatory follicle on day 4 of dominance and assigned to oocyte nucleus stage II; the retraction of the ooplasm from the zona pellucida is considered an artefact of the embedding process. NE, nuclear envelope; N, nucleoli. (d) Oocyte recovered from a preovulatory follicle on day 12 of dominance (N10-Dom), obtained $18 \mathrm{~h}$ after implant removal (follicular phase) and assigned to metaphase I. Chromosomes (arrow) are arranged in metaphase configuration. (e) Oocyte recovered from a preovulatory follicle on day 4 of dominance and assigned to metaphase II; a polar body (PB) is visible in the perivitelline space demonstrating chromosomes (arrow). Scale bar represents $15.4 \mu \mathrm{m}$. 
Table 3. Light microscopical evaluation of nuclear maturation in oocytes recovered from heifer preovulatory follicles with a duration of dominance of $4(n=12)$ or 12 days with maintained dominance $(n=8)$

\begin{tabular}{|c|c|c|}
\hline \multirow[b]{2}{*}{ Oocyte nuclear stage } & \multicolumn{2}{|c|}{ Duration of dominance } \\
\hline & 4 days & 12 days \\
\hline \multicolumn{3}{|c|}{ Before germinal vesicle breakdown: } \\
\hline Oocyte nuclear stage I & $0 / 12^{n}$ & $0 / 8^{\mathrm{a}}$ \\
\hline Oocyte nuclear stage II & $11 / 12^{\mathrm{a}}$ & $1 / 8^{\mathrm{b}}$ \\
\hline \multicolumn{3}{|c|}{ After germinal vesicle breakdown: } \\
\hline Metaphase I & $0 / 12^{\text {a }}$ & $6 / 8^{\mathrm{b}}$ \\
\hline Metaphase II & $1 / 12^{\mathrm{a}}$ & $1 / 8^{a}$ \\
\hline
\end{tabular}

abProportions with different superscripts within rows are significantly different $(P<0.05)$.

Table 4. Light microscopical evaluation of cytoplasmic maturation in oocytes recovered from heifer preovulatory follicles with a duration of dominance of $4(n=12)$ or 12 days with maintained dominance $(n=8)$

\begin{tabular}{|c|c|c|}
\hline \multirow[b]{2}{*}{ Characteristics of intracellular organelles } & \multicolumn{2}{|c|}{ Duration of dominance } \\
\hline & 4 days & 12 days \\
\hline \multicolumn{3}{|l|}{ Mitochondria: } \\
\hline Number & $1.1 \pm 0.1^{\mathrm{a}}$ & $1.7 \pm 0.2^{b}$ \\
\hline Location: central & $3 / 12^{\mathrm{a}}$ & $8 / 8^{\mathrm{b}}$ \\
\hline Location: peripheral & $12 / 12$ & $7 / 8$ \\
\hline Appearance: diffuse & $5 / 12^{a}$ & $8 / 8^{b}$ \\
\hline Appearance: clusters & $11 / 12^{\mathrm{a}}$ & $2 / 8^{b}$ \\
\hline Association with lipid droplets & $10 / 12^{\mathrm{x}}$ & $3 / 8^{y}$ \\
\hline \multicolumn{3}{|l|}{ Lipid droplets: } \\
\hline Number & $0.9 \pm 0.1^{a}$ & $1.4 \pm 0.2^{\mathrm{b}}$ \\
\hline Location: central & $1 / 12^{\mathrm{a}}$ & $8 / 8^{\mathrm{b}}$ \\
\hline Location: peripheral & $11 / 12^{a}$ & $6 / 8^{a}$ \\
\hline Appearance: diffuse & $2 / 12^{\mathrm{a}}$ & $6 / 8^{b}$ \\
\hline Appearance: clusters & $9 / 12^{x}$ & $2 / 8 y$ \\
\hline \multicolumn{3}{|l|}{ Vesicles: } \\
\hline Number & $2.4 \pm 0.2^{\mathrm{a}}$ & $2.0 \pm 0.2^{\mathrm{a}}$ \\
\hline Location: central & $12 / 12$ & $8 / 8$ \\
\hline Location: peripheral & $12 / 12$ & $7 / 8$ \\
\hline Appearance: diffuse & $12 / 12$ & $8 / 8$ \\
\hline Appearance: clusters & $0 / 12$ & $0 / 8$ \\
\hline Size & Mainly large, even & Small to large, uneven \\
\hline \multicolumn{3}{|l|}{ Vacuoles: } \\
\hline Number of oocytes affected & $0 / 12^{a}$ & $4 / 8^{b}$ \\
\hline Location & - & Central \\
\hline Size & - & Large \\
\hline
\end{tabular}

Different superscripts within rows indicate significant differences $\left({ }^{(a b} P<0.05 ; " v \leq 0.1\right)$.

nuclear envelope and vacuolation of nucleoli, as reported from the first dominant follicle after luteolysis but before the endogenous LH surge (Hyttel et al., 1987, 1997; Assey et al., 1993). Thus, early nuclear changes are initiated before the gonadotrophin surge, and are necessary for ribosomal RNA transcription and the synthesis of proteins needed to achieve GVBD and chromatin condensation (Sirard et al., 1989; Kastrop et al., 1991; Fissore et al., 1996; Lévesque and Sirard, 1996).

Chromatin condensation and dispersion were seen in oocytes recovered from persistent first dominant follicles (Revah and Butler, 1996) and associated with less maturation promoting factor kinase activity (Revah et al., 1997). In the present study, the majority of oocytes recovered from follicles that were dominant for 12 days had progressed to metaphase I. Future studies are needed to determine whether such oocytes experience difficulty in progressing to metaphase II as seen in oocytes recovered from atretic sheep follicles (Moor and Trounson, 1977), or whether the prolonged interval from metaphase I to fertilization influences cytoplasmic maturation and oocyte developmental capacity. The retraction of the cumulus cell process endings was more obvious in metaphase oocytes, and may block the transmission of meiosis-inhibitory substances from granulosa 
cells to the oocyte (Downs, 1993). The shift in organelle distribution within the oocyte from a peripheral location to a more diffuse and random appearance seen in the present study also signifies that communication with the surrounding cumulus layer has been interrupted irreversibly. Further studies are required to determine what causes the disconnection between oocyte and cumulus cells (leading to final oocyte maturation) in dominant follicles after prolonged periods of dominance. In this context, it is interesting to note that oocytes from persistent dominant follicles in the present study had a similar low degree of cumulus cell expansion to that observed in oocytes recovered from follicles with a short duration of dominance, despite having progressed to metaphase. In addition, no changes in intrafollicular steroids (reduction in oestradiol associated with increase in progesterone) and total $\alpha$-inhibin (increase) were seen indicative of dominant follicle luteinization after the gonadotrophin surge (Sunderland $e t$ al., 1996; Bigelow and Fortune, 1998). In contrast, final oocyte maturation was associated with continued dominance of $74 \%$ persistent dominant follicles, with loss of dominance in $26 \%$ persistent dominant follicles, and with intrafollicular alterations (reduction in oestrogen activity and increased inhibin A concentrations) that have been related to follicle atresia (Guilbault et al., 1993; Ireland et al., 1994; Sunderland et al., 1996). In particular, inhibin A concentrations in follicular fluid have been correlated positively with amounts of the $34 \mathrm{kDa}$ inhibin dimer, and are increased in atretic antral follicles, the first dominant follicle after loss of dominance and subordinate follicles after dominant follicle selection (Guilbault et al., 1993; Ireland et al., 1994; Sunderland et al., 1996; Mihm et al., 1997). Oocytes recovered from subordinate follicles after dominant follicle selection demonstrate GVBD and metaphase configuration of chromosomes; a process termed 'pseudomaturation' (Assey et al., 1993). Therefore, it appears that the present study lends support to the hypothesis that persistent follicles undergo gradual atresia and render oocytes that are able to be fertilized, but have impaired developmental competence (Ahmad et al., 1995).

However, as yet, the exact relationship between the oocyte and its respective intrafollicular environment is undetermined. The physiological state of follicles appears to affect subsequent oocyte maturational competence in vitro and in vivo (Moor and Trounson, 1977; Grimes and Ireland, 1986; Bar-Ami et al., 1994; Hazeleger et al., 1995). Asynchrony of follicle and oocyte maturation occur after superovulation, and may reduce oocyte developmental competence (Hyttel et al., 1986; de Loos et al., 1991). The role of intrafollicular inhibin or activin in bovine oocyte maturation is equivocal (Tsafiri et al., 1989; Van Tol et al., 1994; Izadyar et al., 1996; Silva and Knight, 1998), and clearly awaits further research. The follicular alterations reported in the present study may be in contrast with other published studies of dominant follicle persistence that describe either no changes in intrafollicular steroids, inhibins and IGF-binding proteins (de la Sota et al., 1994, 1996) or enhanced progesterone synthesis (Revah and Butler, 1996; Bigelow and Fortune, 1998). Differences in the ability of the various progestagen models to maintain dominant follicle growth and steroidogenesis for long periods may be due to differences in LH pulse frequencies achieved, and the duration of the exogenously maintained dominance period.

The increasing LH stimulation in the physiological follicular phase is essential for protein synthesis and further cytoplasmic maturation of oocytes, so that normal meiosis and fertilization can be completed (Assey et al., 1994), yet it is not known when nuclear activation occurs during this period. Rat oocytes undergo premature maturation as a result of additional $\mathrm{LH}$ stimulation with subsequent detrimental effects on pregnancy rates (Mattheij et al., 1994). In the present model, LH pulse frequency determined in heifers in the mid-luteal phase was slightly higher (one pulse every $2.5 \mathrm{~h}$ ) compared with previous studies (in general, one pulse every $3-4 \mathrm{~h}$ ), but remained constant at one pulse approximately every $2 \mathrm{~h}$ for the complete duration of the progestagen implant. It has been suggested that exposure to an LH pulse frequency of 1 pulse every 1-2 hours for an extended time period (Cooperative Regional Research Project, NE-161, 1996), in cattle, can initiate maturational changes in the oocyte (Revah and Butler, 1996), and may also cause the onset of follicle luteinization (Bigelow and Fortune, 1998). In addition, it is proposed that subtle differences in the rate of increase in LH pulse frequency during dominant follicle persistence may determine dominant follicle function and oocyte fate. LH pulse frequencies that gradually increase over a very prolonged period may cause the onset of luteinization, whereas failure to maintain a sufficient rate of increase (present study) may lead to subtle reductions in follicle health ( $74 \%$ of dominant follicle) or even loss of dominance ( $26 \%$ of dominant follicle). If these conditions persist for longer than 9 days, communication between oocyte and follicle cells may be disrupted in most cases, and final oocyte maturation is induced in the absence of the gonadotrophin surge. However, ovulatory ability of such persistent dominant follicles is maintained and will lead to ovulation of aged oocytes which, in agreement with Revah and Butler (1996), may be responsible for significantly reduced pregnancy rates.

The authors gratefully acknowledge the excellent help of A. Baguisi with aspirations, E. Fitzpatrick with preparations, and $\mathrm{H}$. Hyttel with evaluation of oocytes. The authors would also like to acknowledge T. Buckley for taking oocyte photographs; the staff of Lyons Estate for the care of animals; Clonatec for provision of progesterone antibody; J. Roser (Department of Animal Science, University of California, Davis, CA) for LH antibody; the NHPP of the NIH for provision of bovine LH standard, FSH antiserum, FSH for iodination and bovine FSH standard; the USDA for provision of LH for iodination; and N. P. Groome for inhibin $\beta_{A}$ antibody.

\section{References}

Ahmad N, Schrick FN, Butcher RL and Inskeep EK (1995) Effect of persistent follicles on early embryonic losses in beef cows Biology of Reproduction $\mathbf{5 2}$ 1129-1135

Alak BM, Smith GD, Woodruff TK, Stouffer RL and Wolf DP (1996) Enhancement of primate oocyte maturation and fertilization in vitro by inhibin A and activin A Fertility and Sterility 66 646-653

Assey RJ, Hyttel P, Greve T and Purwantara B (1993) Oocyte structure in dominant and subordinate follicles Molecular Reproduction and Development 37 335-344 
Assey RJ, Hyttel P, Roche JF and Boland MP (1994) Oocyte structure and follicular steroid concentrations in superovulated versus unstimulated heifers Molecular Reproduction and Development 39 8-16

Austin EJ, Mihm M, Ryan MP, Williams D and Roche JF (1998) Controlling duration of dominance of the ovulatory follicle: effects on fertility and synchrony of oestrus Proceedings of the 24th Meeting of the Irish Grassland and Animal Production Association pp 3-4

Badinga L, Driancourt MA, Savio JD, Wolfenson D, Drost M, de la Sota RL and Thatcher WW (1992) Endocrine and ovarian responses associated with the first-wave dominant follicle in cattle Biology of Reproduction 47 871-883

Bar-Ami S, Zlotkin E, Brandes JM and Itskovitz-Eldor J (1994) Failure of meiotic competence in human oocytes Biology of Reproduction 50 1100-1107

Bigelow KL and Fortune JE (1998) Characteristics of prolonged dominant versus control follicles: follicle cell numbers, steroidogenic capabilities, and messenger ribonucleic acid for steroidogenic enzymes Biology of Reproduction 58 1241-1249

Cooke DJ, Crowe MA and Roche JF (1997) Circulating FSH isoform patterns during recurrent increases in FSH through the oestrous cycle of heifers Journal of Reproduction and Fertility $110339-345$

Cooperative Regional Research Project, NE-161 (1996) Relationship of fertility to patterns of ovarian follicular development and associated hormonal profiles in dairy cows and heifers Journal of Animal Science $\mathbf{7 4}$ 1943-1952

Crowe MA, Padmanabhan V, Hynes N, Sunderland SJ, Enright WJ, Beitins IZ and Roche JF (1997) Validation of a sensitive radioimmunoassay to measure serum follicle-stimulating hormone in cattle: correlation with biological activity Animal Reproduction Science 48 123-136

de la Sota RL, Good TEM, Ireland JLH, Ireland JJ, Simmen FA and Thatcher WW (1994) Analysis of different forms of intrafollicular inhibin and inhibin $\alpha$-subunits during ovarian follicular dominance in cattle Biology of Reproduction 50 (Supplement) 429 (Abstract)

de la Sota RL, Simmen FA, Diaz T and Thatcher WW (1996) Insulin-like growth factor system in bovine first-wave dominant and subordinate follicles Biology of Reproduction 55 803-812

de Loos FAM, Bevers MM, Dieleman SJ and Kruip Th AM (1991) Follicular and oocyte maturation in cows treated for superovulation Theriogenology 35 $537-546$

Downs SM (1993) Factors affecting the resumption of meiotic maturation in mammalian oocytes Theriogenology 39 65-79

Drost M, Savio JD, Barros CM, Badinga $L$ and Thatcher WW (1992) Ovariectomy by colpotomy in cows Journal of the American Veterinary Association 200 337-339

Fissore RA, Chang Li He and Vande Woude GF (1996) Potential role of mitogen-activated protein kinase during meiosis resumption in bovine oocytes Biology of Reproduction 55 1261-1270

Frei RE, Schultz GA and Church RB (1989) Qualitative and quantitative changes in protein synthesis occur at the 8-16-cell stage of embryogenesis in the cow Journal of Reproduction and Fertility 86 637-641

Grimes RW and Ireland JJ (1986) Relationship of macroscopic appearance of the surface of bovine ovarian follicles, concentrations of steroids in follicular fluid, and maturation of oocytes in vitro. Biology of Reproduction 35 725-732

Guilbault LA, Rouillier P, Matton RG, Glencross RG, Beard AJ and Knight PG (1993) Relationship between the level of atresia and inhibin contents ( $\alpha$ subunit and $\alpha-\beta$ dimer) in morphologically dominant follicles during their growing and regressing phase of development in cattle Biology of Reproduction 48 268-276

Hazeleger NL, Hill DJ, Stubbings RB and Walton JS (1995) Relationship of morphology and follicular fluid environment of bovine oocytes to their developmental potential in vitro. Theriogenology 43 509-522

Hill JR, Jr, Lamond DR, Henricks DM, Dickey JF and Niswender GD (1971) The effect of melengestrol acetate (MGA) on ovarian function and fertilization in beef heifers Biology of Reproduction 416-22

Hyttel P and Madsen I (1987) Rapid method to prepare mammalian oocytes and embryos for transmission electron microscopy Acta Anatomica 129 $12-14$

Hyttel P, Callesen H and Greve T (1986) Ultrastructural features of preovulatory oocyte maturation in superovulated cattle fournal of Reproduction and Fertility 76 645-656

Hyttel P, Xu KP, Smith S, Callesen H and Greve T (1987) Ultrastructure of the final nuclear maturation of bovine oocytes in vitro. Anatomica Embryologica 17635-40

Hyttel P, Fair T, Callesen H and Greve T (1997) Oocyte growth, capacitation and final maturation in cattle Theriogenology 47 23-32
Ireland JJ and Roche JF (1983) Development of nonovulatory antral follicles in heifers: changes in steroids in follicular fluid and receptors for gonadotropins Endocrinology 112 150-156

Ireland JLH, Good TEM, Knight PG and Ireland JJ (1994) Alterations in amounts of different forms of inhibin during follicular atresia Biology of Reproduction $501265-1276$

Izadyar F, Zeinstra E, Colenbrander B, Vanderstichele HMJ and Bevers MM (1996) In vitro maturation of bovine oocytes in the presence of bovine activin A does not affect the number of embryos Animal Reproduction Science 45 37-45

Kastrop PMM, Hulshof SCJ, Bevers MM, Destrée OHJ and Kruip Th AM (1991) The effects of alpha-amanitin and cycloheximide on nuclear progression, protein synthesis, and phosphorylation during bovine oocyte maturation in vitro. Molecular Reproduction and Development 28 249-254

Knight PG and Muttukrishna S (1994) Measurement of dimeric inhibin using a modified two-site immunoradiometric assay specific for oxidised (Met $\mathrm{O}$ ) inhibin Journal of Endocrinology 141 417-425

Knight PG, Beard AJ, Wrathall JHM and Castillo RJ (1989) Evidence that the bovine ovary secretes large amounts of monomeric inhibin $\alpha$ subunit and its isolation from bovine follicular fluid Journal of Molecular Endocrinology 2 189-200

Lévesque JT and Sirard M-A (1996) Resumption of meiosis is initiated by the accumulation of cyclin B in bovine oocytes Biology of Reproduction 55 1427-1436

Manikkam M and Rajamahendran R (1997) Progesterone-induced atresia of the proestrous dominant follicle in the bovine ovary: changes in diameter, insulin-like growth factor system, aromatase activity, steroid hormones, and apoptotic index Biology of Reproduction 57 580-587

Matteri RL, Roser JF, Baldwin DM, Lipovetsky V and Papkoff H (1987) Characterization of a monoclonal antibody which detects luteinizing hormone from diverse mammalian species Domestic Animal Endocrinology 4 157-165

Mattheij JAM, Swarts JJM, Hurks HMH and Mulder K (1994) Advancement of meiotic resumption in Graafian follicles by LH in relation to preovulatory ageing of rat oocytes Journal of Reproduction and Fertility 100 65-70

Merriam GR and KW Wachter (1982) Algorithms for the study of episodic hormone secretion American Journal of Physiology 243 E310-E318

Merriam GR and KW Wachter (1984) Measurement and analysis of episodic hormone secretion. In Computers in Endocrinology Vol. 14 pp 325-346 Eds D Rodbard D and G Forti. Serono Symposia, Raven Press, New York

Mihm M, Baguisi A, Boland MP and Roche JF (1994) Association between the duration of dominance of the ovulatory follicle and pregnancy rate in beef heifers Journal of Reproduction and Fertility 102 123-130

Mihm M, Good TEM, Ireland JLH, Ireland JJ, Knight PG and Roche JF (1997) Decline in serum follicle-stimulating hormone concentrations alters key intrafollicular growth factors involved in selection of the dominant follicle in heifers Biology of Reproduction 57 1328-1337

Moor RM and Trounson AO (1977) Hormonal and follicular factors affecting maturation of sheep oocytes in vitro and their subsequent developmental capacity Journal of Reproduction and Fertility 49 101-109

Prendiville DJ, Enright WJ, Crowe MA, Finnerty M, Hynes N and Roche JF (1995) Immunization of heifers against gonadotropin releasing hormone: antibody titers, ovarian function, body growth and carcass characteristics Journal of Animal Science 73 2382-2389

Rahe CH, Owens RE, Fleeger JL, Newton HJ and Harms PG (1980) Pattern of plasma luteinizing hormone in the cyclic cow: dependence upon the period of the cycle Endocrinology 107 498-503

Revah I and Butler WR (1996) Prolonged dominance of follicles and reduced viability of bovine oocytes Journal of Reproduction and Fertility 106 39-47

Revah I, Presicce GA, Senatore E, Ignotz G and Butler WR (1997) MPF phosphorylating activity in oocytes and development and function of corpora lutea derived from persistent follicles in dairy cows journal of Reproduction and Fertility Abstract Series 19 Abstract 172

Ronayne E and Hynes N (1990) Measurement of plasma progesterone concentrations by extraction and non-extraction radioimmunoassays Irish Journal of Agricultural Research 29 109-115

Sanchez T, Wehrman ME, Bergfeld EG, Peters KE, , Kojima FN, Cupp AS, Mariscal V, Kittok RJ, Rasby RJ and Kinder JE (1993) Pregnancy rate is greater when the corpus luteum is present during the period of progestin treatment to synchronize time of estrus in cows and heifers Biology of Reproduction 49 1102-1107

Savio JD, Thatcher WW, Badinga L, de la Sota RL and Wolfenson D (1993) Regulation of dominant follicle turnover during the oestrous cycle in cows Journal of Reproduction and Fertility 97 197-203 
Silva C and Knight PG (1998) Modulatory actions of activin A and follistatin on the developmental competence of in vitro matured bovine oocytes Biology of Reproduction 58 558-565

Sirard MA, Florman HM, Leibfried-Rutledge ML, Barnes FL, Sims ML and First NL (1989) Timing of nuclear progression and protein synthesis necessary for meiotic maturation in bovine oocytes Biology of Reproduction 40 1257-1263

Smith LC, Olivera-Angel M, Groome NP, Bhatia B and Price CA (1996) Oocyte quality in small antral follicles in the presence or absence of a large dominant follicle in cattle Journal of Reproduction and Fertility 106 193-199

Stock AE and Fortune JE (1993) Ovarian follicular dominance in cattle: relationship between prolonged growth of the ovulatory follicle and endocrine parameters Endocrinology 132 1108-1114

Stock AE, Woodruff TK and Smith LC (1997) Effects of inhibin A and activin A during in vitro maturation of bovine oocytes in hormone- and serum-free medium Biology of Reproduction 56 1559-1564

Sunderland SJ, Knight PG, Boland MP, Roche JF and Ireland JJ (1996)
Alterations in intrafollicular levels of different molecular weight forms of inhibin during development of follicular and luteal phase dominant follicles in heifers Biology of Reproduction 54 453-462

Taylor C, Rajamahendran R and Walton JS (1993) Ovarian follicular dynamics and plasma luteinizing hormone concentrations in norgestomettreated heifers Animal Reproduction Science 32 173-184

Tsafiri A, Vale W and Hsueh AJW (1989) Effects of transforming growth factors and inhibin-related proteins on rat preovulatory Graafian follicles in vitro. Endocrinology $1251857-1862$

Van Tol HTA, Loos de FAM, Vanderstichele HMJ and Bevers MM (1994) Bovine activin-A does not affect the in vitro maturation of bovine oocytes Theriogenology $41673-679$

Wishart DF (1977) Synchronization of oestrus in heifers using steroid (SC5914, SC9880 and SC21009) treatment for 21 days 2 . The effect of treatment on the ovum collection and fertilisation rate and the development of the early embryo Theriogenology 8 249-269 